\title{
BIOLOGIA DE SUPELLA LONGIPALPA (FABRICIUS) (DICTYOPTERA: BLATELLIDAE) EM DIETA ARTIFICIAL E ASSOCIAÇÃO COM MICRO-ORGANISMOS PATOGÊNICOS AO HOMEM
}

\author{
E. Corrêa, N. Silva, J. Bentes
}

Universidade Federal do Amazonas, Faculdade de Ciências Agrárias, Laboratório de Entomologia e Acarologia Agrícola, Av. Gen. Rodrigo Otávio Jordão, 300, CEP 69070-000, Manaus, AM, Brasil. E-mail: eneidacorrea@bol.com.br

\section{RESUMO}

Foi estudada a biologia de Supella longipalpa (Fabricius) e seu potencial de contaminação por fungos e bactérias. As coletas foram realizadas em residências localizadas em três bairros: Nossa Senhora das Graças, Betânia e Alvorada na Cidade de Manaus, AM. Foram obtidas 13,6 ninfas por ooteca, com um período de retenção das ootecas no corpo da fêmea de 39,2 horas e intervalo de liberação entre ootecas de 134,4 horas. No estágio ninfal foram obtidos cinco estádios com $68,5 \%$ de viabilidade. A razão sexual foi de 49,6 com o período pré-reprodutivo de 6 dias e média de 6,7 ootecas por fêmea. O ciclo total de desenvolvimento foi, em média, de 218,56 dias. Nos estágios ninfal e adulto (macho e fêmea) foi registrada a prevalência de associação com fungos pertencentes aos gêneros Penicillium e Aspergillus e bactérias gram-negativas Enterobacter e Klebsiella prevalecendo nos três bairros analisados.

PALAVRAS-CHAVE: Insecta, blatódeos, ciclo de vida, patógenos.

\begin{abstract}
BIOLOGY OF SUPELLA LONGIPALPA (FABRICIUS) (DICTYOPTERA: BLATELLIDAE) ON ARTIFICIAL DIET AND ITS ASSOCIATION WITH MICROORGANISMS PATHOGENIC TO HUMANS. The present study was aimed at assessing the biological parameters of Supella longipalpa (Fabricius), as well as its potential for being contaminated by fungi and bacteria. Collections were carried out in households located in three neighborhoods: Nossa Senhora das Graças, Betânia and Alvorada in the city of Manaus, state of Amazonas, Brazil. An average of 13.6 nymphs were obtained per ootheca with a retention period of 39.2 hours on the female's body and a release interval from one ootheca to the other in 134.4 hours. Five nymph instars with $68.5 \%$ viability were obtained in the nymph stage. The sex ratio was 49.6 with a pre-reproductive period of 6 days and an average of 6.7 oothecae per female. The entire developing cycle lasted 218.56 days. In the nymph and adult stages (male and female), there was found a prevalence of association with fungi from the genera Penicillium and Aspergillus and gram-negative bacteria with Enterobacter and Klebsiella genera prevailing in the three neighborhoods.
\end{abstract}

KEY WORDS: Insecta, cockroach, life cycle, pathogens.

\section{INTRODUÇÃO}

Originária do continente africano, Supella longipalpa (Fabricius, 1978) (Dictyoptera: Blatellidae) é uma barata típica de ambiente intradomiciliar. Está amplamente disseminada nas regiões Neotropical e Afrotropical (CoRnwell, 1968). No Brasil, o gênero Supella teve sua ocorrência registrada primeiramente por ReHN (1916). Na região amazônica foi constatada por Albuquerque (1964) no Estado do Pará e, em 1972, no Amazonas (Albuqueroue, 1972). É uma das menores baratas urbanas. O macho adulto apresenta corpo alongado enquanto a fêmea é mais larga, relativamente arredondada na porção distal do abdome, apresentando variações nos padrões de cores. As asas do macho cobrem completamente o abdome, mas, no caso da fêmea, raramente atingem a sua extremidade (CORNWELL, 1968).

Os blatódeos sinantrópicos são importantes vetores mecânicos de patógenos, estando associados à transmissão de diversas doenças como: dermatites, asma brônquica ealergias em indivíduos suscetíveis (VIANNA et al., 2000). Micro-organismos que causam essas doenças são transportados nas pernas e no corpo das baratas, sendo depositados nos alimentos e utensílios por onde forrageiam (BENNET et al.,1988). 
Dentre os principais micro-organismos associados, destacam-se as bactérias, fungos, helmintos e protozoários. Estudos referentes a micro-organismos patogênicos associados às baratas são comuns na literatura para as espécies Periplaneta americana (Linnaeus) e Blatella germanica (Linnaeus) (Rотн; Willis, 1957; Guthrie; Tindal, 1968; BROOKS; STRAND, 1977; PÉReZ, 1989; Fotedar et al., 1991; PRADO, 2002; PAi et al., 2003).

Entretanto, para S. longipalpa esses estudos são escassos, sendo de grande interesse devido à ampla distribuição desta espécie em ambientes domiciliares e hospitalares e ao hábito alimentar onívoro, podendo se constituir em importante agente de disseminação de micro-organismos de interesse médico (Albuduerque, 1964; Mariconi, 1999, Pellens; GRANDCOLAS, 2008; RAFAEL et al., 2008). Este trabalho objetivou estudar a biologia de S. longipalpa em dieta artificial e avaliar a ocorrência de associações entre esta espécie com bactérias e fungos com potencial patogênico ao homem.

\section{MATERIAL E MÉTODOS}

\section{Biologia de S. longipalpa}

Os estudos de biologia foram realizados em câmara climatizada regulada à temperatura de $28 \pm 2^{\circ}$ C; $80 \pm 2 \%$ de UR e escotofase de $24 \mathrm{~h}$.

Para iniciar a criação estoque, foram feitas coletas em três bairros na Cidade de Manaus, AM, [Nossa Senhora das Graças (S 03 05' 83" ; W 60 $01^{\prime}$ $\left.52^{\prime \prime}\right)$, Betânia (S $03^{\circ} 08^{\prime} 29^{\prime \prime}$; W $60^{\circ} 00^{\prime} 71^{\prime \prime}$ ) e Alvorada (S $03^{\circ} 04^{\prime} 45^{\prime \prime}$; W $\left.60^{\circ} 03^{\prime} 19^{\prime \prime}\right)$ ], onde previamente havia sido detectado alto índice de ocorrência de $S$. longipalpa, com base em informações de empresas controladoras de pragas urbanas. Foram coletadas 60 ootecas e 20 fêmeas com ootecas, em ambientes domiciliares, principalmente em cozinhas. A coleta foi feita manualmente utilizando frascos de vidro de $250 \mathrm{~mL}$ esterilizados.

No laboratório, as ootecas e fêmeas foram individualizadas em copos descartáveis de $250 \mathrm{~mL}$, devidamente etiquetados e cobertos com tela de filó. Após eclosão, as ninfas foram mantidas agregadas até a emergência dos adultos, sendo em seguida individualizados em 20 casais para fins de avaliação dos parâmetros biológicos. Ninfas e adultos foram transferidos para copos descartáveis $(500 \mathrm{~mL})$ e alimentados com grânulos deração comercial para gatos $\left(\right.$ Gatuche $^{\circledR}$ ) previamente esterilizada em autoclave a $121^{\circ} \mathrm{C}$ durante 15 minutos, trocados a cada dois dias. A água foi fornecida em chumaços de algodão esterilizado umedecido em água destilada.

Os parâmetros biológicos avaliados foram: número de ecdises, mortalidade de ninfas, emergên- cia de adultos e longevidade de machos e fêmeas. Foram utilizadas 121 ootecas obtidas de fêmeas da criação estoque, que foram individualizadas em copos descartáveis, sendo observadas diariamente.

Foram determinados o período de retenção da ooteca (período entre o início da exposição da ooteca e sua liberação), o número de ootecas por fêmea, o número de ninfas por ooteca, o intervalo entre a liberação de uma ooteca e a subsequente e a razão sexual $\left(\mathrm{n}^{\circ}\right.$ defêmeas $/ \mathrm{n}^{\circ}$ demachos $+\mathrm{n}^{\circ}$ defêmeas). Registros morfométricos das ootecas foram obtidos por meio de uma lâmina graduada com precisão de $0,1 \mathrm{~mm}$.

Para a determinação do número de estádios ninfais e da viabilidade ninfal, periodicamente, as exúvias foram removidas de modo a evitar sua ingestão pelas respectivas ninfas. Foram feitos registros do horário de forrageamento de ninfas e adultos.

Para a avaliação da longevidade de machos e fêmeas, após prévia sexagem, vinte casais foram individualizados em recipientes plásticos transparentes $(500 \mathrm{~mL}$ para registro da longevidade de machos e fêmeas). Registrou-se o período préreprodutivo referente ao intervalo compreendido entre a emergência das fêmeas e o início de exposição da ooteca.

A análise de variância dos dados foi realizada utilizando o programa Statistica versão 6 e a comparação entre as médias foi feita pelo teste de Tukey $(\mathrm{P} \leq 0,05)$.

\section{Associação entre $S$. longipalpa com fungos e bactérias}

Para estudos da associação de S. longipalpa a fungos e bactérias, nas residências de cada bairro foram coletados 10 indivíduos machos, 10 fêmeas e 10 ninfas de diferentes estádios, que foram acondicionados individualmente em frascos de vidro previamente autoclavados e esterilizados em estufa a $120^{\circ} \mathrm{C}$, durante 8 horas. Os espécimes foram levados ao laboratório onde procedeu-se o isolamento dos micro-organismos.

Oisolamento de fungos a partir dos espécimes coletados foi realizado segundo metodologia adaptada de PRADO (2002). Cada espécime foi transferido para tubos de ensaio contendo $10 \mathrm{~mL}$ de solução salina a $0,8 \%$ esterilizada e, posteriormente, agitados com auxílio do Vortex por 20 segundos para liberação dos esporos aderidos ao corpo do espécime. Foi depositada uma alíquota de $0,2 \mathrm{~mL}$ da solução do lavado de cada indivíduo em 3 placas de Petri contendo meios de cultura BDA (Batata-dextrose-ágar) e Saboraud acrescido de antibióticos (Ampicilina $100 \mathrm{mg} / \mathrm{L} \mathrm{e}$ Cloranfenicol $250 \mathrm{mg} / \mathrm{L}$ ) para prevenir ocrescimento de bactérias contaminantes. O lavado restante foi imediatamente submetido à autoclavagem a $120^{\circ}$ C durante 20 minutos. Após o resfriamento, foi de- 
positado $0,2 \mathrm{~mL}$ do lavado autoclavado em 3 placas de Petri, contendo os meios já mencionados, constituindo na testemunha do ensaio. As placas foram mantidas em incubadora com temperatura de $27 \pm$ $2^{\circ} \mathrm{C}$ durante 24 a 48 horas. Ao surgirem os primeiros fragmentos de hifas, estas foram transferidas para novas placas de Petri contendo os mesmos meios de cultura, para individualização das colônias. Os isolados obtidos foram quantificados e mantidos em tubos de ensaios com meio de cultura em incubadora a $18 \pm 2^{\circ} \mathrm{C}$, sendo posteriormente identificados por meio da observação de estruturas reprodutivas, em microscópio de luz, e o com auxílio de chaves taxonômicas disponíveis na literatura (BARNETT; HUNTER, 1972; CARMichaEl et al., 1980; HANLIN, 1990).

\section{Isolamento de bactérias}

Para o isolamento de bactérias, a partir dos espécimes, foi utilizada a mesma metodologia descrita para o isolamento de fungos. Foram utilizados os meios de cultura ágar MacConkey e NA (nutrienteágar) acrescido de fungicida Benlate $(0,1 \mathrm{~mL} / 100 \mathrm{~L}$ de meio) e Nistatina $(0,1 \mathrm{~mL} / 100 \mathrm{~mL}$ de meio) para prevenir o crescimento de fungos contaminantes. O controle do ensaio foi o mesmo utilizado para fungos. As placas foram mantidas em incubadora com temperatura de $37 \pm 2^{\circ} \mathrm{C}$ durante 24 a 48 horas. Ao surgirem as primeiras colônias de bactérias, estas foram transferidas para novas placas contendo os meios decultura, para individualização das colônias. Esses isolados foram quantificados e mantidos em tubos de ensaio, contendo o meio NA em incubadora a $18 \pm 2^{\circ} \mathrm{C}$. Foi realizado o teste de Gram de acordo com Alves (1998), distinguindo-se os isolados Gram positivos e Gram negativos. A identificação das bactérias foi feita por meio de testes bioquímicos de: produção de Indol, indicador de gás sulfídrico $\left(\mathrm{H}_{2} \mathrm{~S}\right)$, motilidade, utilização de citrato e fermentação de açucares (glicose, lactose e sacarose) segundo EwING (1986). Inicialmente as colônias foram cultivadas em ágar BHI (caldo nutriente, infusão de cérebro e coração) durante 24 horas para rejuvenescimento; em seguida, semeadas em placas contendo meio EMB (eosina azul de metileno) durante 24 horas. As reações bioquímicas foram realizadas usando-se os meio TSI (ágar-açúcar tríplice e ferro), citrato e $\mathrm{SIM}\left(\mathrm{H}_{2} \mathrm{~S} /\right.$ Indol/motilidade) em estufa a $37 \pm 2^{\circ} \mathrm{C}$ durante $24 \mathrm{~h}$.

\section{RESULTADOS E DISCUSSÃO}

\section{Parâmetros biológicos}

Dentre as 121 ootecas utilizadas, metade $(49,6 \%)$ mostrou-se viável. É possível que esta baixa viabilidade esteja associada às condições microclimáticas e má formação de ootecas.

As médias deootecas por fêmea eninfas por ooteca foram 6,7 e13,6, respectivamente (Tabela 1). A ooteca fica retida na extremidade do abdome da fêmea (Fig. 1A) por um período de 39,2 horas. Este tempo de retenção, relativamente longo, está associado à intensa atividade de forrageamento, o que garante um maior potencial de dispersão intradomiciliar das ootecas. O intervalo de liberação entre uma ooteca e a subsequente foi de 5,6 dias. O intervalo entre a liberação da ooteca e eclosão das ninfas foi de 49,59 dias. Estes parâmetros foram convergentes aos obtidos por CoRnwell (1968) e SCHAll et al. (1984), exceto para o período de retenção da ooteca, que foi de 18 horas. Foram registrados cinco a sete estádios ninfais, sendo que a maioria das ninfas $(88,5 \%)$ desenvolveu-se em cinco estádios. O período de desenvolvimento ninfal foi, em média, de 79,04 dias. Não houve diferença significativa entre a duração dos estádios ninfais (Tabela 2).

Em geral, os valores dos parâmetros biológicos referentes a este estágio mostraram-se similares aos obtidos por Gould; Deay (1940); CoRnwell (1968); ScHAll et al. (1984); para essa espécie. Estes autores registraram média de 6 a 8 estádios ninfais em temperaturas que variaram de $24^{\circ} \mathrm{C}$ a $30^{\circ} \mathrm{C}$.

A viabilidade ninfal foi de $68,5 \%$ corroborando com Willis et al. (1958) que registraram média de $75 \%$. Observou-se uma redução no número médio deninfas por ooteca relacionado ao período reprodutivo, a partir da $2^{a}$ ooteca, com oscilações na $7^{\mathrm{a}}$ e $9^{\mathrm{a}}$ apresentando uma drástica redução na $10^{\mathrm{a}}$ ooteca (Fig. 2). Wiluis et al. (1958) registraram redução de ninfas na $7^{\circ}$ ooteca.

Tabela 1 - Média de ninfas e ootecas, período de retenção no corpo da fêmea e intervalo entre liberação e eclosão ( \pm erro padrão) de ninfas de Supella longipalpa criada com ração comercial (Gatuche ${ }^{\circledR}$ ). Temp. $28 \pm 2{ }^{\circ}$ C, UR $80 \pm 2 \%$, escotofase: $24 \mathrm{~h}$.

\begin{tabular}{cccc}
\hline$N^{\circ}$ ooteca/fêmea & $\mathrm{N}^{\circ}$ ninfas/ooteca & $\begin{array}{c}\text { Tempo de retenção em } \\
\text { horas }\end{array}$ & $\begin{array}{c}\text { Intervalo entre liberação e } \\
\text { eclosão em dias }\end{array}$ \\
\hline $6,7 \pm 3,08$ & $13,6 \pm 3,46$ & $39,2 \pm 9,91$ & $49,4 \pm 3,60$ \\
$(4-10)$ & $(4-18)$ & $(24-96)$ & $(42-55)$ \\
{$[121]$} & {$[784]$} & {$[121]$} & {$[121]$} \\
\hline
\end{tabular}

${ }^{1}$ Valores entre parênteses expressam o intervalo de variação.

${ }^{2}$ Valores entre colchetes representam o número de observações. 
Tabela 2- Diferença de duração dos estádios ninfais de Supella longipalpa, criadas com ração comercial (Gatuche ${ }^{\circledR}$ ). Temp.: $28 \pm 2^{\circ}$ C, UR $80 \pm 2 \%$, escotofase: $24 \mathrm{~h}$.

\begin{tabular}{ccc}
\hline Estádios & $\mathrm{F}$ & $\mathrm{p}$ \\
\hline I & 2,91 & 0,00 \\
II & 0,91 & 0,00 \\
III & 0,205 & 0,00 \\
IV & 0,304 & 0,00 \\
V & 0,37 & 0,00 \\
VI & 0,67 & 0,00 \\
VII & 0,45 & 0,01 \\
\hline
\end{tabular}

${ }^{1}$ Valores de [F] e [p] para cada estádio ninfal, com base na análise de variância (ANOVA).

Tabela 3 - Duração média, em dias, ( \pm erro padrão) do desenvolvimento de Supella longipalpa, criada com ração comercial (Gatuche ${ }^{\circledR}$ ). Temp.: $28 \pm 2^{\circ}$ C, UR $80 \pm 2 \%$, escotofase: $24 \mathrm{~h}$.

\begin{tabular}{lccc}
\hline Ooteca & Período ninfal & Adulto & Ciclo total \\
\hline $59,09 \pm 4,18$ & $79,04 \pm 3,74$ & $93,2 \pm 22,35$ & $218,56 \pm 5,79$ \\
$(48-66)$ & $(67-86)$ & $(60-122)$ & $(237-249)$ \\
{$[60]$} & {$[516]$} & {$[15]$} & {$[15]$} \\
\hline
\end{tabular}

${ }^{1}$ Valores entre parêntesis expressam o intervalo de variação

${ }^{2}$ Valores entre colchete representam o número de observações
No estágio adulto o processo de emergência e pigmentação ocorreu em 45 minutos, com os adultos recém-emergidos apresentando coloração branca. Os machos emergiram, geralmente, antes das fêmeas. As ninfas e adultos tornam-se mais ativos, no intervalo entre 23 horas e 4 horas da manhã. A razão sexual é de um macho para uma fêmea. A longevidade média dos adultos acasalados foi de 93,2 dias, sendo 95 dias para machos e 91 dias para fêmeas, a variação da longevidade entre machos e fêmeas apresentou uma diferença significativa $(t=7,20 ; \mathrm{F}=1,42$ e $\mathrm{p}=0,73)$. Gould; DeAy (1940) e Willis et al. (1958) registraram 90 e 115 dias para machos e 95 e 90 dias para fêmeas, respectivamente, convergindocom os valores obtidos no presente trabalho. Ociclo total de desenvolvimento deooteca a adultofoi, em média, 218,56 dias (Tabela3). Operíodo pré-reprodutivo foi de 6 dias, envolvendo a maturação sexual e pré-formação das ootecas. ScHALL etal. (1984) registraram à temperatura de $24^{\circ} \mathrm{C}, 10$ dias para o período pré-reprodutivo, diferindo assim dos dados obtidos neste trabalho.

Adultos machos e fêmeas mediram 14,3 mm e $12,3 \mathrm{~mm}$ de comprimento, respectivamente. $\mathrm{O}$ dimorfismo sexual se manifesta no tamanho das asas e formato do abdome. As fêmeas apresentam asas curtas e abdome volumoso e arredondado em relação aos machos (Fig. 1B).
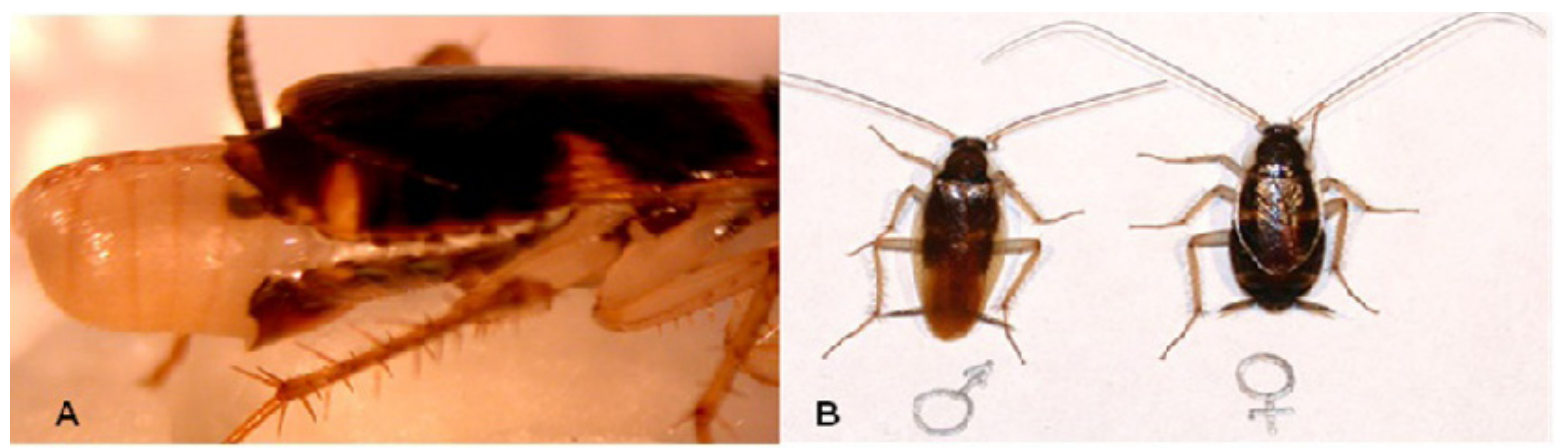

Fig.1. - A) Ooteca retida na extremidade abdominal da fêmea de Supella longipalpa; B) Dimorfismo sexual de S. longipalpa.

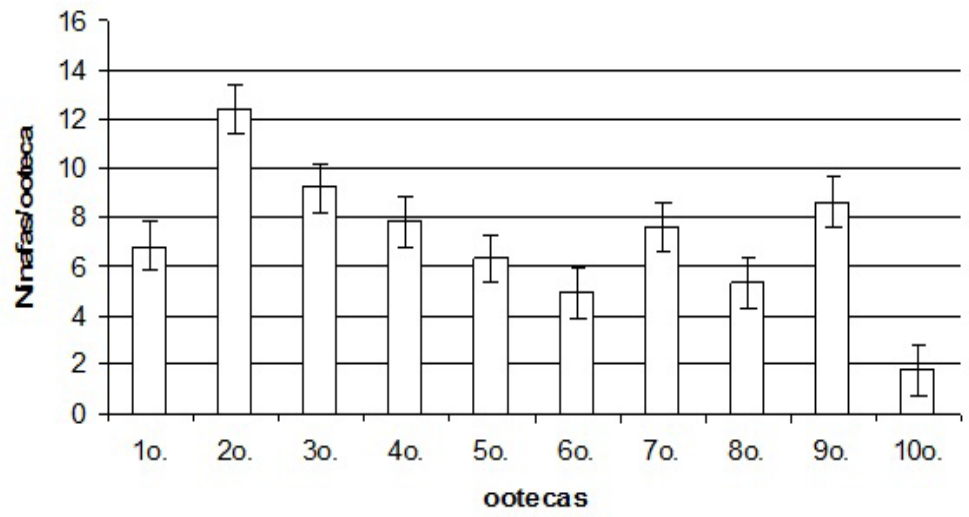

Fig.2 - Média e Erro Padrão de ninfas por ooteca produzidas por fêmeas de Supella longipalpa criadas com ração comercial (Gatucheß) Temp. $28 \pm 2^{\circ}$ C, UR $80 \pm 2 \%$, escotofase: 24 h. Obs.: Valores baseados no número máximo de ootecas (10) produzidas pelas fêmeas. 

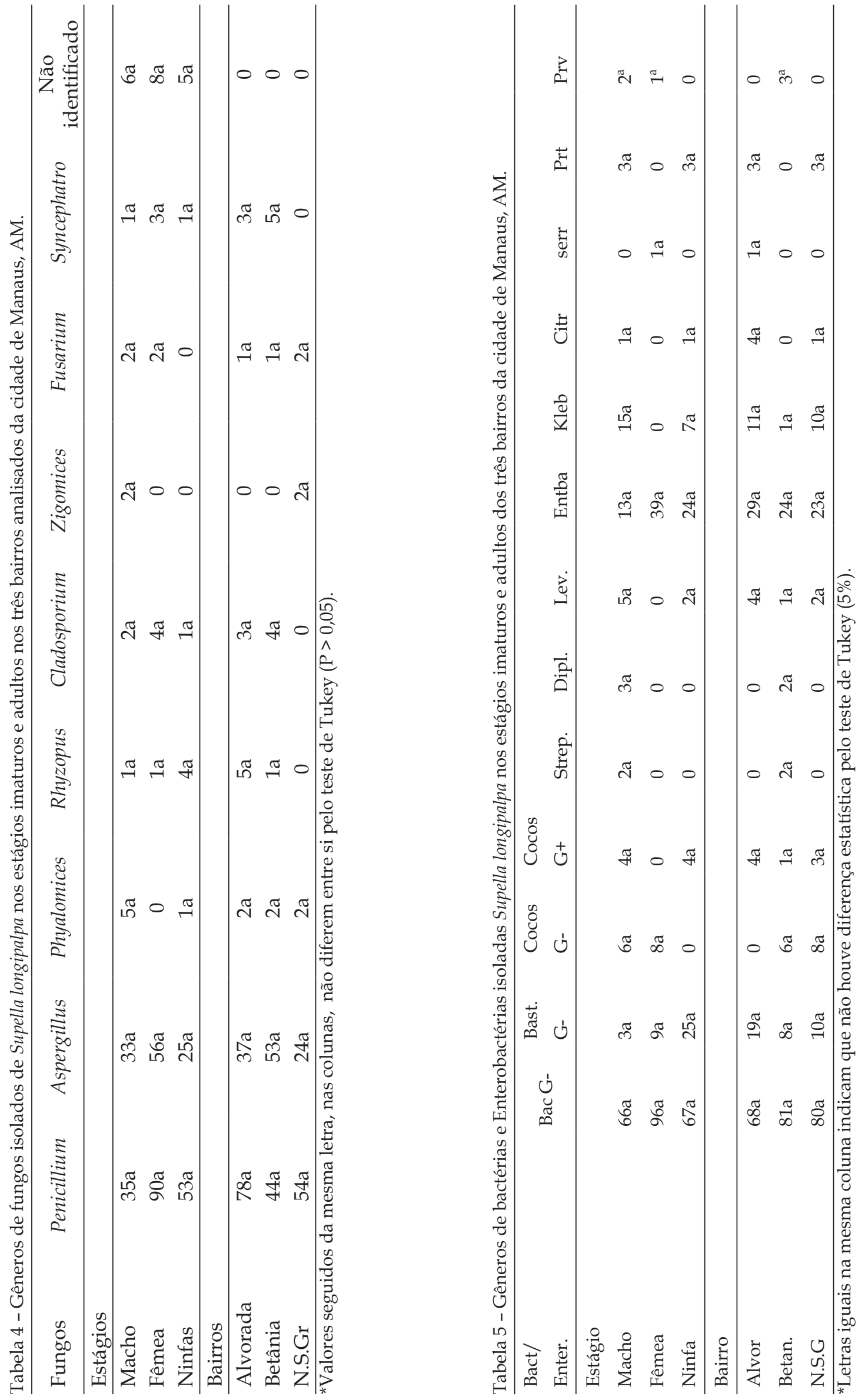
Isolamento de fungos e bactérias de S. longipalpa

Foram identificados sete gêneros de fungos isolados das baratas: Aspergillus, Penicillium, Phyalomices, Syncephastro, Fusarium, Cladosporium, e Rhyzopus. A presença destes gêneros foi comum nos bairros estudados. Os gêneros predominantes foram Penicillium e Aspergillus isolados tanto das formas imaturas quanto adultas de S. longipalpa. Estes fungos destacam-se por apresentarem potencial patogênico ao homem. SINGH; Kumar (2002) registraram que baratas são vetores mecânicos de fungos dos gêneros Aspergillus e Penicillium, produzindo alergia que pode causar hipersensibilidade. A maioria dos espécimes de $S$. longipalpa foi coletada na cozinha das residências localizadas nos três bairros. Ofato de as baratas forragearem principalmente nessa área, que apresenta maior oferta de alimento, abrigo e umidade, a proliferação de fungos tende a ser elevada (LOPES, 2005). As fêmeas apresentaram maior número de isolados de fungos com elevada ocorrência de Penicilium, enquanto que os machos apresentaram maior diversidade de gêneros de fungos. Esta elevada associação está provavelmente relacionada ao comportamento de forrageamento diferenciado desses blatódeos, que é mais expressiva entre as ninfas e fêmeas de S. longipalpa. As fêmeas apresentaram reduzida atividade de voo, sobretudo quando estão transportando ootecas. Por sua vez, os machos forrageiam menos, porém, voam com mais frequência, possibilitando contato com superfícies de vários ambientes intradomiciliares, o que pode contribuir para ampliação da diversidade de ocorrência de gêneros de fungos associados ao exoesqueleto. Não houve diferença significativa na quantidade de fungos isolados das fases imaturas e adultas nos bairros estudados (Tabela 4).

Quantoàs bactérias, foramidentificados 229 bacilos Gram-negativos, 37 bastonetes gram-negativo, 8 cocos gram-positivos e 14 cocos gram-negativos. Cento e treze isolados foram identificados como enterobactérias pertencentes a cinco gêneros de bastonetes gramnegativos Entéricos (Enterobacteriaceae): Klebsiella, Enterobacter, Providencia, Proteus e Citrobacter.

Entre as enterobactérias isoladas, o gênero Enterobacter teve maior evidência nos três bairros, seguidos do gênero Klebsiella com reduzida ocorrência no bairro da Betânia. PRADO (2002) isolou espécies desses dois gêneros em exoesqueleto de $P$. americana em grandes quantidades em ambiente hospitalar.

Os bacilos gram-negativos ocorreram em maior número, com distribuição uniforme nos três bairros.

Os gêneros Citrobacter, Enterobacter, Proteus, e Klebsiella foram registrados em associação com espécimes imaturos e adultos de S. longipalpa em ambiente domiciliar. Ressalta-se que essas bactérias são mais frequentes em ambiente hospitalar.
Rivault et al. (1991) isolaram do trato intestinal de S. longipalpa em hospital, as espécies de bactérias: Citrobacter freundii (Werkman e Gillen), Enterobacter cloacal (Jordan), Klebsiella oscytica (Flugge) e Klebsiella pneumoniae (Schroeter). O gênero Citrobacter foi isolado do exoesqueleto de S. longipalpa em dois bairros: Nossa Senhora das Graças e Alvorada, em quantidade reduzida. O maior número de isolados de bactérias foi obtido em ninfas, fêmeas e machos de $S$. longipalpa, com destaque para o gênero Enterobacter. As fêmeas apresentaram maior número de isolados de bactérias com elevada ocorrência de bacilos gram-negativos. Os machos apresentaram maior diversidade de gêneros de bactérias isoladas (Tabela 5).

\section{CONCLUSÕES}

S. longipalpa possui elevado potencial biótico, apresentando mais de uma geração por ano. Possui comportamento de intensa dispersão, facilitado pela fixação das ootecas. É vetor mecânico de fungos com predominância para os gêneros Penicillium e Aspergillus, ebactérias, predominando os gêneros Enterobacter e Klebsiella, importantes na saúde pública. Sendo espécie intradomiciliar, transporta um grande número de bactérias do gênero Klebsiella, a qual é comumente encontrada em ambiente hospitalar. As bactérias e fungos encontrados na superfície do exoesqueleto de S. longipalpa refletem, indiretamente, o status sanitário dos intradomicílios nos bairros analisados.

\section{REFERÊNCIAS}

ALBUQUERQUE, I.R.S. Check-list dos Blattaria brasileiros. Boletim do Museu Paraense Emilio Goeldi. Série Zoologia, v.41, p.1-37, 1964.

ALBUQUERQUE, I.R.S. Inventário dos Blattaria da Amazônia com descrição de três novas espécies. Boletim do Museu Paraense Emilio Goeldi. Série Zoologia, v.76, p.138, 1972.

ALVES, S.B. Controle Microbiano de Insetos. 2.ed. Piracicaba: Fealq, 1998. 1163p.

BARNETT, H.L.; HUNTER, B.B. Illustrated genera of imperfect fungi. 3.ed. Minneapolis: Burgess Publishing, 1972. 241p.

BENNET, G.W.; OWENS, J.M.;CORRIGAN, R.M. Truman's scientific guide to pest control operations. Duluth, MN: Edgell Commun, 1988. 495p.

BROOKS, M.A.; STRAND, M.A.Pathogens of Blattidae (Cockroaches). Bulletin of the World Health Organization, v.55, p.289-296, 1977. 
CARRERA, 1991. Referência citada , mas não está nesta lista. CARMICHAEL, J.W; KENDRICK, W.B.; CONNERS, I.L.; SIGLER, L. Genera of Hydromycetes. Edmonton: The University of Alberta Press, 1980. 386p.

CORNWELL, P.B. The Cockroach. London: Hutching 1968. v.1. 390p.

EWING, W.H. Edward and Ewings's Identification of Enterobacteriaceae 4.ed. New York: Elsevier, 1986.

FOTEDAR, R.; SHRINIWAS, U.B.; VERNA, A. Cockroaches (Blatella germanica) as carriers of microorganisms of medical importance in hospitais. Epidemiology and Infection, v.107, n.1, p.181-187, 1991.

GOULD, G.E.; DEAY, H.O. The biology of six species of cockroaches which in habit buildings. Bulletin Agricultural Experiment Station Purdue University, 1940. 451p.

GUTHRIE, D.M.; TINDAL, A.R. The biology of cockroach. London: Edward Arnold Publ, 1968.408p.

HANLIN, R.T. Ilustrated genera of ascomycetes.2.pt St. Paul: The American Phytopathological Society, 1990. 263p.

LOPES, R.B. Controle de Blatella germânica (L.) com Metharhizium anisoplie e inseticidas reguladores de crescimento. 2005. 121p. Tese (Doutorado - Entomologia Agrícola) - Escola Superior de Agricultura "Luiz de Queiroz" Universidade de São Paulo, Piracicaba, 2005.

MARICONI, F.A.M. (Coord.). Insetos e outros invasores de residências. Piracicaba: FEALQ, 1999. 460p. (Biblioteca de Ciências Agrárias Luiz de Queiroz, v.6).

PAI, H.H.; KO, Y.C.; CHEN, E.R. Cochroaches (Periplaneta americana and Blatella germanica) as potencial mechanical disseminators of Entamoeba hystolitica. Acta Tropica, v.87, p.355-359, 2003.

PELLENS, R.; GRANDCOLAS, P. Catalogue of Blattaria (Insecta) from Brazil. Zootaxa, v.1709, p.1-109, 2008.

PÉREZ, J.R. La Cucaracha como vetor de agentes patógenos. Boletin de la Oficina Sanitaria Panamericana, v.107, n.1, p.41-53, 1989.
PRADO, M.A. Microrganismos isolados de baratas (Periplaneta americana) em um hospital público de grande porte do Centro-Oeste. 2002. 67p. Dissertação (Mestrado) - Faculdade de Enfermagem, Universidade Federal de Goiás, Goiania, 2002.

RAFAEL, J.A.; SILVA, N.M.; DIAS, R.M.N.S. Baratas (Insecta, Blattaria) Sinantrópicas na Cidade de Manaus, Amazonas, Brasil. Acta Amazônica, v.38, n.1, p.173-178, 2008.

REHN, J.A.G.G. The Standford Expedition to Brazil in 1911. Transactions of the American Entomological Society, v.42, p.215-308, 1916

RIVAULT, C.; CLOAREC, A.; LEGUYADER, A. Bacterial load of cockroaches in relation to urban environment. Transport de bactéries par les Blattes en Milieu Urban. Bulletin de la Societe Zoologique de France. Evolution et Zoologie, v.116, p235-241, 1991

ROTH, L.M.; WILLIS, E.R. The reproduction of cockroaches. Smithsonian Miscellaneous Collections, v.12, p.1-49, 1954.

ROTH, L.M.; WILLIS, E.R. The Medical and Veterinary importance of cockroaches. Smithsonian Miscellaneous Collections, v.134, p.1-147, 1957.

SCHALL, C.J.; GAUTIER, J.Y.; BELL, W.J. Behavioural Ecology of cockroaches. Biological Reviews, v.59, p.209254,1984

SINGH,A.B.; KUMAR, P. Common environment allergens causing respiratory allergy. Indian Journal of Pediatrics, v.69, n.3, p.245, 2002.

VIANNA, E.E.S.; BERNE, M.E.A.; CHERNAKI, A.M.; RIBEIRO, P.B. Perfomance Reprodutiva de Periplaneta americana (Linneu 1758) (Blattodea:Blatidae). Arquivos do Instituto Biológico, São Paulo, v.67, n.1, p.99-107, 2000.

WILLIS, E.R.; RISER, G.R.; ROTH, M.L.M. Observations on reproduction and development in cockroaches. Annals of the Entomological Society of America, v.51, p.53-69, 1958.

Recebido em $7 / 4 / 10$

Aceito em 18/8/11 